\title{
2021 Annual Meeting Update
}

\author{
ASHLEY VANDE BUNTE | AMERICAN POLITICAL SCIENCE ASSOCIATION
}

W

e are pleased to announce that APSA's 2021

Annual Meeting will return to an in-person meeting in Seattle this year while also offering a virtual option. Over the course of the past few months, we have worked closely with many stakeholders to design a plan to allow for a safe and accessible meeting in 2021. Focus groups were held at the end of last year with division chairs, section chairs, and status committee chairs to solicit feedback on various options. Monthly meetings were held with the 2021 program chairs, Valeria Sinclair-Chapman (Purdue University) and Dino P. Christenson (Washington University in St. Louis) to develop a plan. In January, the Executive Committee and the Meetings Policy Committee reviewed the plan to move forward.

We are pleased to create a plan for a meeting that is safe, inclusive, and accessible for the entire discipline during this challenging time. Adapting the meeting format model will bring together political scientists in an innovative way and allow for attendees to pick a format that works best for their circumstances. It is more important than ever to bring together the discipline to share the latest research and scholarship, provide opportunities for scholars to learn about the job market, and be able to network with one another.

\section{The response to the call for papers has been robust and we are looking forward to showcasing a wide array of discussions and debates in the discipline across the many panels, plenaries, roundtables, mini- conferences, and short courses proposed for this year's annual meeting!}

On the annual meeting, program co-chairs Valeria Sinclair-Chapman and Dino P. Christenson commented "Navigating the changing circumstances of the pandemic is an ongoing challenge, but, fortunately, we are in good hands working with the APSA staff and Council. The response to the call for papers has been robust and we are looking forward to showcasing a wide array of discussions and debates in the discipline across the many panels, plenaries, roundtables, mini-conferences, and short courses proposed for this year's annual meeting! After

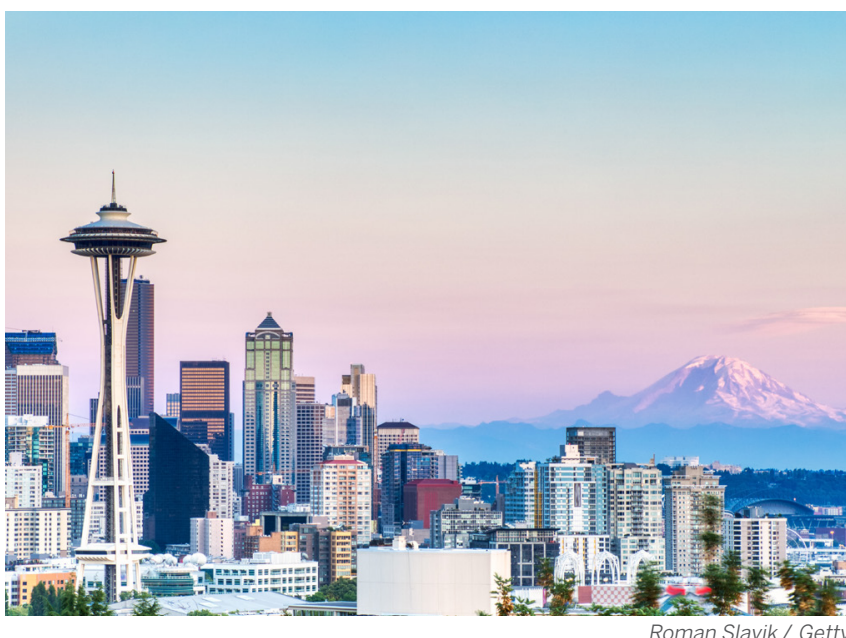

what feels like eons apart, we are excited to safely reconvene in person this October in Seattle!"

This year's annual meeting will feature a number of panels on the conference theme of "Promoting Pluralism," as well as special plenary addresses by Commissioner Thomas Hicks on "Running an Election During a Pandemic" and Professor Scott E. Page on "Appreciating and Leveraging the Diversity of Political Science." Hicks was nominated by President Barack H. Obama and confirmed unanimously by the United States Senate on December 16, 2014 to serve on the United States Election Assistance Commission (EAC). He has served twice as chairman of the commission and will assume the position of vice chair later this month. He serves as the designated federal officer for the Board of Advisors. Page is the John Seely Brown Distinguished University Professor of Complexity, Social Science, and Management at the University of Michigan and recipient of a Guggenheim Fellowship and a fellowship at the Center for Advanced Studies in the Behavioral Sciences at Stanford. Scott was elected a fellow of the American Academy of Arts and Sciences in 2011, and in 2019, he was awarded a Distinguished University Professorship from the University of Michigan, the university's highest academic honor.

We will continue to monitor pandemic developments in Seattle, the United States, and the world throughout the coming months, and will aim to provide up to date information in a timely manner. In the coming weeks, we will release further information regarding planning for business meetings, receptions, short courses, interview services, and ancillary events. For the latest updates on the meeting, visit connect.apsanet.org/apsa2021 - 